\title{
Antibodies generated against dextransucrase exhibit potential anticariostatic properties in Streptococcus mutans
}

\author{
Shabeer Ahmad Rather ${ }^{1}$. Sukesh Chander Sharma ${ }^{1} \cdot$ Akhtar Mahmood $^{1}$ (D) \\ Received: 18 September 2019/Revised: 11 December 2019 / Accepted: 18 December 2019 / Published online: 3 January 2020 \\ (C) Springer-Verlag GmbH Germany, part of Springer Nature 2020
}

\begin{abstract}
Streptococcus mutans is a common principal causative agent of dental caries. In this communication, we describe that the antibodies raised against purified dextransucrase effectively inhibited the growth of $S$. mutans. The purified enzyme showed 58-fold enrichment, $17.5 \%$ yield and a specific activity of 3.96 units $/ \mathrm{mg}$ protein. Purified IgG fraction of the antibody showed significant affinity with the antigenic protein. Immunotritation of the enzyme with dextransucrase antibody showed a gradual increase in inhibition of dextransucrase activity. The growth of $S$. mutans was also inhibited by $85 \%$ in the presence of $28 \mu \mathrm{g}$ of $\operatorname{IgG}$ fraction of the antibody. Antibodies also impaired glucosyltransferase activity $(72.8 \%)$ and biofilm formation by $92.6 \%$ in S. mutans. Western blot analysis revealed no cross reactivity with the various tissues of mice, rat, rabbit and humans. Dot blot analysis showed little reactivity with Lactobacillus acidophilus and Staphylococcus aureus and there was no reactivity with other bacterial strains like Enterococcus faecalis, Escherichia coli and Salmonella typhimurium. These findings suggest that antibody raised against dextransucrase exhibit inhibitory effects on the growth of $S$. mutans and biofilm formation with no reactivity with various mammalian tissues, thus it could be an effective anticariogenic agent.
\end{abstract}

Keywords Dextransucrase $\cdot$ Dental caries $\cdot$ Streptococcus mutans $\cdot$ Antibody $\cdot$ Biofilm $\cdot$ Anticariogenic agent

\section{Introduction}

Dental caries is globally the most prevalent disease of mankind causing demineralisation of tooth enamel by acids produced by the oral bacteria (Yang et al. 2017; Talbman and Smith 1974). It is a multifactorial biofilm-mediated disorder, which is initiated by dysbiosis in the biofilm complex, where certain bacteria take the dominance over others in the oral flora. It has been shown that many bacteria are involved in the genesis of caries formation at different stages. Among these Streptococcus mutans is the primary causative agent of dental caries (Alam et al. 2018).

Akhtar Mahmood

akhtarmah@yahoo.com

Shabeer Ahmad Rather

rathershabeer@gmail.com

Sukesh Chander Sharma

sukeshcs@pu.ac.in

1 Department of Biochemistry, Panjab University, Sector 14, Chandigarh 160014, India
S. mutans is an acidogenic and aciduric microorganism, well characterised to produce dental caries (Loesche 1996). It has the ability to generate large quantities of extracellular polysaccharides (dextrans) from sucrose under the action of dextransucrase (EC.2.4.1.5)/glucosyltransferases (GTFs) accompanied with its adhesion and acid-producing activities (Lynch et al. 2013). These dextrans help in the attachment of microbe to tooth surface leading to infection (Kuramitsu 1974).

A number of compounds such as penicillin, cationic agents (chlorhexidine), plant products (polyphenols, flavonoids, anionic agents (sodium dodecyl sulphate) and non-ionic agents (triclosan) have been used for the prevention of dental caries by inhibiting growth and adherence of these cariogenic bacteria to the tooth surface (Jarvinen et al. 1993; Chen and Wang 2010). But these organisms are either resistant to them (Alam et al. 2018; Bhattacharya et al. 2003) or the drugs exhibit side effects (Craig 1998).

Studies on the prevention of cariogenicity have also focussed on antibody production and hence vaccine development from adaptive immunity. For vaccine development, attention was paid on the purified antigens involved in the pathogenesis of dental caries for the development of potentially safer vaccines, which may reduce the viability of bacteria in the saliva, impairing the 
surface adhesion and inhibiting the metabolically active enzymes involved in caries formation (Chen and Wang 2010).

Many surface molecules of $S$. mutans such as lipoteichoic acid, glucosyltransferases (GTFs), antigen A (a 29-kDa protein antigen), antigen $\mathrm{C}$ (a 70-kDa protein antigen), antigen D (a 13$\mathrm{kDa}$ protein antigen), AgI/II (a 190-kDa protein), AgIII (39-kDa protein), GbP (glucan-binding protein) (Kruger 2004), GtfB (Kim et al. 2012) and DNA-based active vaccines, synthetic peptides and mucosal adjuvants (heat-labile enterotoxins (HLT) from Vibrio cholera (LT-I) or Escherichia coli (LT-II), bupivacaine, chitosan) have attracted great attention for passive immunisation in the prevention of the dental caries (Yan 2013; Chen and Wang 2010; Fan et al. 2002; Xu et al. 2007; Alam et al. 2018). Fusion vaccines (pGJA-p/VAX and pGJG/GAC/VAX) encoding PAc and GLU of $S$. mutans were also tested in gnobiotic animals (Kt et al. 2013) and flagellin-PAc fusion protein (KF-rPAc) was also tested in rats for anticaries vaccine (Bao et al. 2015). Antibodies raised against recombinant form of substrate binding component of the phosphate uptake system (rPstS) of S. mutans have shown protective response against caries formation (Ferreira et al. 2016). Cao et al. (2016) found no significant effect of specific s-IgA antibody on caries formation. Yang et al. (2019) developed the intranasal cold-adapted influenza vaccine, which was limited by the large size of the vector than S. mutans epitope, this resulted in memory immune response thus reducing the duration and intensity of exogenous antigens. Among the various proteins of $S$. mutans, dextransucrase has an essential role in the synthesis of glucan from sucrose, thus play a crucial role in the pathogenesis of the caries (Talbman and Smith 1974).

Strategies of using adaptive immunity for the generation of antibodies against various purified molecules of $S$. mutans have shown encouraging results related to dental caries protection, but were limited by the cross-reactive epitopes against human heart and skeleton muscle tissues as detected by indirect immunofluorescence and crossed immunoelectrophoresis (Kt et al. 2013). Hajishengallis and Michalek (1999) however reported that glucosyltransferase when tested for cross reactivity with human heart tissue showed negative results.

In the present study, we have tried to evaluate the effect of anti-dextransucrase antibodies on caries formation by using purified dextransucrase as the antigen from $S$. mutans. The evaluation of anti-dextransucrase antibodies demonstrated that they inhibited several of the cariogenic characteristics of S. mutans, thus have the potential for development of anticaries agent. Some of these results are described in this communication.

\section{Materials and methods}

\section{Ethical issue}

The study was approved by Central Animal Ethics Committee Panjab University Chandigarh (IAEC no. PU/IAEC/S/16/52).
All experiments were performed in compliance with the guidelines of Committee for the Purpose of Control and Supervision of Experiments on Animals (CPCSEA). Tissues from various animals were obtained from the department of Zoology Panjab University Chandigarh. Human tissues were obtained from the histopathology department of Postgraduate Institute of Medical Education and Research Chandigarh in compliance with the standards of institutional ethical committee.

\section{Chemicals}

Chemicals used in this study were of analytical grade. Freund's adjuvants complete and incomplete, electrophoresis reagents were purchased from Sigma Chemical Co. (St. Louis, MO, USA). Agar, brain heart infusion broth (BHI), exogenous dextrose, glucose, sucrose, peptone and maleic acid, $\mathrm{NaCl}$ and ethanol were obtained from HiMedia Pvt. Ltd. (Mumbai, India). Sephadex G-200 and all other chemicals used were obtained from E. Merck Pvt. Ltd. (Mumbai, India) or Sisco Research Lab Pvt. Ltd. (Mumbai, India).

\section{Bacterial strains and growth conditions}

S. mutans strain MTCC-890 and Streptococcus oralis MTCC2696 used in this study were obtained from MTCC Institute of Microbial technology (IMTECH), Chandigarh, India. Lactobacillus acidophilus MTCC-10307, Staphylococcus aureus ATCC-9144, Salmonella typhimurium NCTC-74 and Escherichia coli MTCC-1610 were obtained from department of Microbiology PU Chandīgarh. Enterococcus faecalis MTCC-439 were obtained from Interdisciplinary Biotechnology Unit, AMU Campus, Aligarh, India. S. mutans strains MTCC-890 were grown in brain heart infusion (BHI) broth, supplemented with $1 \%$ dextrose, $1 \%$ peptone, $0.29 \%$ glucose, $0.25 \%$ sodium hydrogen phosphate and $0.05 \% \mathrm{NaCl}(\mathrm{pH} 7.4)$ to late-exponential phase at $37{ }^{\circ} \mathrm{C}$. S. oralis was grown in Tryptic Soy Agar (TSA) (HiMedia, Mumbai, India). E. coli, S. aureus and S. typhimurium were grown in Nutrient agar at $37^{\circ} \mathrm{C}$ and L. acidophilus was grown in MRS media (Sisco Research Laboratories Pvt. Ltd., New Mumbai, India). All studies relating to dextransucrase were carried out using MTCC-890 strain of S. mutans.

\section{Antigen preparation}

Antigenic protein dextransucrase was purified from culture supernatant of $S$. mutans MTCC-890 by ammonium sulphate precipitation followed by Sephadex G-200 column chromatography. The pooled fractions from column chromatography were treated with PEG-400. After centrifugation at $15,000 \mathrm{~g}$ to separate the dextransucrase fraction, the pellet was dissolved in $10 \mathrm{mM}$ sodium maleate buffer (pH 6.8) dialysed overnight 
using Dialysis Membrane-135 (HiMedia, Mumbai, India) (Liu et al. 2010). The dialysate obtained served as the antigen. Except otherwise stated all procedures were carried out at $4{ }^{\circ} \mathrm{C}$ (Goyal 2015). Concentrations of the purified proteins were detected by Bradford protein assay (Campion et al. 2017). The purity of dextransucrase protein was assessed by SDSPAGE (Laemmli 1970).

\section{Enzyme assays}

Dextransucrase activity was assayed by using standard reaction mixture containing $0.05 \mathrm{M}$ sodium maleate buffer (pH 6.8), 0.1 M sucrose, in total volume of $0.5 \mathrm{ml}$. After incubation for $30 \mathrm{~min}$ at $37^{\circ} \mathrm{C}$, the samples were assayed for glucose using the Glucostat kit (Reckon Diagnostic P. LTD.). The results were expressed in enzyme units per milligram of protein. One unit of dextransucrase activity was defined as the amount of enzyme required to release $1 \mu \mathrm{mol}$ of glucose per min under standard assay conditions.

\section{Animals}

New Zealand White Rabbits 6-8 months old were purchased from animal facility of Indian Institute of Microbial technology (IMTECH), Chandigarh, India. Animals were kept in the animal facility of the department of Biochemistry Panjab University Chandigarh under specific-pathogen-free (SPF) conditions. They were housed in a metallic cage and were provided with food and water ad libitum. Animal studies were performed in compliance with the guidelines of Committee for the Purpose of Control and Supervision of Experiments on Animals (CPCSEA).

\section{Immunisation of animals}

Six-month old New Zealand white rabbits were immunised subcutaneously with purified dextransucrase protein $(500 \mathrm{mg} / \mathrm{ml})$ emulsified in Freund's Complete Adjuvant (F5881, Sigma, USA). The injection sites were clipped and disinfected with $70 \%$ alcohol before injections were made. The injections of around $250 \mu \mathrm{l}$ each were given at four different sites in the limbs. Blood sample of $2 \mathrm{ml}$ was taken before injection. Serum was collected from blood by centrifugation for analysis. Booster injections were given post immunisation after 3 weeks and repeated again after 4 weeks and 6 weeks using the antigen emulsified with Freund's incomplete adjuvant. Test bleeds were taken after 8 days of each booster and checked for serum antibody using dot blot assay. Sera was collected 2 weeks after injecting the booster immunisation dose for the analysis of dextransucrase antibody. Presence of serum antibody raised against dextransucrase antibody was checked by dot blot analysis (Vera-Cabrera et al. 1999).

\section{Dot blot assay}

Dot blot assay was performed by spotting $2 \mu \mathrm{l}$ of samples slowly to minimise area onto the nitrocellulose membrane at the centre of the grid drawn by a pencil. The membrane was allowed to dry at room temperature and non-specific sites were blocked by soaking in 5\% Skim milk in Phosphate buffered saline tween-20 (PBST) for $2 \mathrm{~h}$ at $37^{\circ} \mathrm{C}$. The membrane was washed three times in phosphate buffered saline (PBS) (NaCl $137 \mathrm{mM}, \mathrm{KCl} 2.7 \mathrm{mM}, \mathrm{Na}_{2} \mathrm{HPO}_{4} 10 \mathrm{mM}, \mathrm{KH}_{2} \mathrm{PO}_{4}$ $1.8 \mathrm{mM}) \mathrm{pH} 7.4$ and overnight incubated at $4{ }^{\circ} \mathrm{C}$ in $1: 50$ dilution of rabbit serum in 5\% skimmed milk. After washing three times with PBS, it was incubated with HRP-conjugated Goat anti-rabbit secondary antibody diluted 1:6000 for $1 \mathrm{~h}$ at $37{ }^{\circ} \mathrm{C}$. Excess secondary antibody was washed three times 10 min each with PBS developed by Enhanced Chemiluminescence System (ECL) and observed under GelDoc UVTech for fluorescence. Samples positive for serum showed black dots and negative showed clear dots.

\section{Confocal microscopy}

To localise the target protein in the cells of S. mutans, immunocytochemistry was performed by culturing bacterial cells on glass coverslips in 6-well culture plates (Greiner Bio-One India Pvt. Ltd.) at $37^{\circ} \mathrm{C}$ for $36 \mathrm{~h}$. After 36-h of growth, the media were aspirated and cells were washed gently with PBS. Cells were fixed in fixation buffer ( $4 \%$ formaldehyde and $0.2 \%$ glutaraldehyde) for $2 \mathrm{~h}$. After fixation, cells were rinsed twice gently with PBS and blocking solution 3\% BSA (bovine serum albumin) was added and incubated for $90 \mathrm{~min}$. Blocking solution was aspirated and cells rinsed with PBS. Primary antibody raised against the target protein diluted in blocking buffer was added and incubated overnight at $4{ }^{\circ} \mathrm{C}$. Primary antibody was aspirated from wells and washed 3times with PBS and FITC (fluorescein isothiocyanate)-tagged secondary antibody (Sigma-Aldrich, USA) diluted in blocking solution was added and incubated for $1 \mathrm{~h}$ at room temperature in the dark. After incubation with secondary antibody, the cells were washed with PBS, counterstained with DAPI (4, 6-diamidino-2-phenylindole) Sigma-Aldrich, USA, diluted 1:5000 in PBS for $1 \mathrm{~min}$ and washed with distilled water. The glass coverslips were mounted using mounting medium cells-side down onto microscope slides. The coverslips were observed under confocal microscope. The experiment were repeated in triplicates.

\section{Serum analysis by ELISA}

Serum collected from immunised rabbits was analysed for dextransucrase-specific antibody titre by ELISA. Flat-bottom 96-well ELISA plates (Nest Biotech co. Ltd., China) were coated with $10 \mu \mathrm{g}$ of antigenic protein in $0.1 \mathrm{M}$ bicarbonate 
buffer (pH 9) and incubated for overnight at $4{ }^{\circ} \mathrm{C}$. Wells were washed three times with PBS- $0.02 \%$ Tween-20 to remove unbound proteins and blocked in 3\% blocking buffer for $2 \mathrm{~h}$. After washing wells with PBS- $0.02 \%$ Tween-20, rabbit serum samples were serially double diluted, loaded in the wells (first well with 1:100 dilution of antibody) and incubated for $2 \mathrm{~h}$ at room temperature. Subsequently, the wells were washed three times with PBS- $0.02 \%$ Tween 20 which was followed by addition of HRP (horseradish peroxidase)-conjugated goat anti-rabbit $\operatorname{IgG}$ (dilution 1:6000) antibody (Genei, Bangalore, India) and incubated for $1 \mathrm{~h}$ at $37{ }^{\circ} \mathrm{C}$. The liquid was aspirated and wells washed three times with PBS- $0.02 \%$ Tween 20. Tetramethyl benzidine (TMB) solution $100 \mu \mathrm{l} /$ well was added for 5-10 min followed by addition of TMB stop solution (Conc. $\left.\mathrm{H}_{2} \mathrm{SO}_{4}\right) 100 \mu \mathrm{l}$ to each well. Absorbance was read at $450 \mathrm{~nm}$ using microplate reader (SYNERGY/HI BioTek, India). The experiment was repeated three times. Values of the dilution giving an O.D reading that was two times of background were determined as the titre.

\section{Purification of serum IgG by affinity chromatography}

IgG fraction from rabbit serum was purified by affinity chromatography by using ready to use prepacked Protein ASepharose Column (Bio Vision, USA) with a binding capacity of $\geq 16 \mathrm{mg}$ rabbit $\mathrm{IgG} / \mathrm{ml}$ protein A-Sepharose with a flow rate of $2.0 \mathrm{ml} / \mathrm{min}$. The column was equilibrated with PBS as binding buffer $(\mathrm{NaCl} 137 \mathrm{mM}$, in $20 \mathrm{mM}$ Na-K phosphate buffer $\mathrm{pH}$ 8.0). The serum sample was diluted with binding buffer in the ratio of 1:1 volumes, mixed well and applied to the column. The flow through was collected and reapplied 4times to the column. The column was washed $4-5$ times with the $\times 5$ volume of binding buffer and the antibodies were eluted with the elution buffer ( $0.1 \mathrm{M}$ citric acid, $\mathrm{pH} 2.75)$. The fractions were collected and neutralised immediately by adding $100 \mu \mathrm{l}$ of $1 \mathrm{M}$ Tris $\mathrm{pH} 9.0$ per ml of eluate. Protein concentration was assayed by measuring the absorbance at $280 \mathrm{~nm}$.

\section{Determination of minimum inhibitory concentration of serum antibody on bacterial growth under in vitro conditions}

The minimum inhibitory concentrations (MIC) of serum antibody against $S$. mutans was determined by microdilution method as described by Hasan et al. (2014). S. mutans was grown in basal $\mathrm{BHI}$ medium with increasing concentrations of serum antibody ranging from 0 to $40 \mu \mathrm{g} / \mathrm{ml}$ at $37{ }^{\circ} \mathrm{C}$ for $24 \mathrm{~h}$ under aseptic conditions. The MIC was the lowest concentration that inhibited the visible growth of the bacteria. However, the bacterial colonies could not be counted as the growth was essentially negligible. All the determinations were performed in triplicates.

\section{Immunotritation of dextransucrase}

Immunotritation of dextransucrase was performed using standard reaction mixture containing $0.05 \mathrm{M}$ sodium maleate buffer ( $\mathrm{pH}$ 6.8), $0.1 \mathrm{M}$ sucrose, in total volume of $0.5 \mathrm{ml}$ in presence of increasing concentrations of $\operatorname{IgG}(0-70 \mu \mathrm{g})$. The reaction mixture was incubated at $37^{\circ} \mathrm{C}$ for $30 \mathrm{~min}$ and assayed for glucose using the Glucostat kit (Reckon Diagnostic P. LTD.). The results were expressed in enzyme units/mg protein.

\section{Western blot analysis}

The tissue samples were placed in ice cold lysis buffer (RIPA Buffer Sigma-Aldrich, USA) (Product Code R 0278) which contained $50 \mathrm{mM}$ Tris- $\mathrm{HCl}, \mathrm{pH} 8.0$, with $150 \mathrm{mM}$ sodium chloride, $1.0 \%$ Igepal CA-630 (NP-40), $0.5 \%$ sodium deoxycholate, and $0.1 \%$ sodium dodecyl sulphate and phosphatase inhibitor cocktails (Sigma-Aldrich, USA). The tissues were lysed by homogeniser and incubated at $4{ }^{\circ} \mathrm{C}$ overnight and centrifuged at $15,000 \mathrm{~g}$ at $4{ }^{\circ} \mathrm{C}$ for $20 \mathrm{~min}$. The supernatant was stored and quantified for protein concentration. The protein lysate was run on 10\% SDS-PAGE and transferred on to nitrocellulose membrane. Western blot analysis was done following the method described by Mahmood et al. (1993). Primary antibody was diluted in the blocking buffer in the ratio of 1:500 (v/v). HRP-conjugated goat anti-rabbit IgG (dilution 1:7000 v/v) was used as the secondary antibody. The membrane was developed by enhanced chemiluminescence (ECL) and the bands were analysed by ImageJ software for densitometry.

\section{Biofilm assay}

To examine the inhibitory effect of serum antibody on biofilm formation by $S$. mutans, biofilm microplate assay was performed by standard protocol (Merritt et al. 2005). S. mutans were grown in BHI (brain heart infusion) supplemented with $5 \%$ sucrose with a concentration of $3-5 \times$ $10^{6} \mathrm{cfu} / \mathrm{ml}$ or culture optical density adjusted to 0.015 at $600 \mathrm{~nm}\left(\mathrm{OD}_{600}\right)$ in 96-well microtitre plates precoated with saliva to mimic the conditions of oral cavity. Sub MIC of serum antibody were added and wells without serum IgG served as control. After incubation at $37{ }^{\circ} \mathrm{C}$ for $20 \mathrm{~h}$, the planktonic cells were decanted and adherent cells were stained with $0.1 \%$ crystal violet solution for $15 \mathrm{~min}$. The wells were washed with PBS twice, dried and the bound dye was extracted by adding $33 \%$ acetic acid to completely destain the wells. Biofilm formation was measured by measuring the absorbance of resuspended solution at $590 \mathrm{~nm}$ on a BioTek microplate reader. 


\section{Cross reactivity of dextransucrase antibody with mammalian tissues}

Cross reactivity of dextransucrase antibody with mammalian tissues was evaluated by western blot analysis. Proteins from different tissues such as the liver, lungs, spleen, heart, kidney and gall bladder of rat, mice, rabbit and human were resolved on $10 \%$ SDS-PAGE. Samples containing $30 \mu \mathrm{g}$ of protein mixed with loading dye and heated for 5 min were loaded in each well and the molecular weight marker was run in a separate lane so as to identify the band of interest during western blotting. Resolved unstained proteins were transferred onto nitrocellulose membrane and detected as described above.

\section{Cross reactivity of antibody with certain oral microorganisms}

Cross reactivity of anti-dextransuccrase antibody was evaluated by using dot blot method. The cell extracts of various bacterial strains were spotted on the nitrocellulose membrane, allowed to dry and placed in 5\% skimmed milk for $2 \mathrm{~h}$ to block non-specific sites. After blocking, the membrane was incubated in serum antibody (dilution 1:500) raised against dextransucrase from $S$. mutans for $1 \mathrm{~h}$ at $37{ }^{\circ} \mathrm{C}$ followed by incubation in HRP-conjugated goat anti-rabbit secondary antibody diluted 1:6000 for $1 \mathrm{~h}$ at $37^{\circ} \mathrm{C}$. The affinity of serum antibody was observed by developing the membrane by chemiluminescence using Gel-Doc UVTech.

\section{Glucosyltransferase activity}

Transferase activity of dextransucrase enzyme was assayed by modified method of Mukasa et al. (1979). An adequate preparation of enzyme solution containing $0.1 \mathrm{M}$ phosphate buffer ( $\mathrm{pH} 6.5$ ), $41.7 \mathrm{mM}$ sucrose, $34.3 \mu \mathrm{m}$ dextran and $0.02 \%$ sodium azide with and without purified anti-dextransucrase antibody was incubated for $15 \mathrm{~h}$ at $37^{\circ} \mathrm{C}$. The mixture was centrifuged at $17,000 \mathrm{~g}$ for $15 \mathrm{~min}$ to collect water-insoluble glucan formed. The water soluble glucan was precipitated with $75 \%$ ethanol and collected by centrifugation at $17,000 \mathrm{~g}$. The glucans formation was determined by phenol sulphuric acid method (Dubois et al. 1956) in which glucose is dehydrated to hydroxyl methyl furfural which forms a yellow brown coloured product with phenol with an absorption maxima at $490 \mathrm{~nm}$. Enzyme activity was expressed in units/mg protein. One unit of glucosyltransferase activity was defined as the amount of the enzyme catalysing the transfer of 1 umole of the glucose to glucan per min.

\section{Results}

\section{Purification of the antigenic protein dextransucrase from S. mutans}

The culture supernatant of $S$. mutans grown at $37{ }^{\circ} \mathrm{C}$ for $36 \mathrm{~h}$ was used as protein source. After 55\% ammonium sulphate precipitation, the dextransuccrase activity was enriched by 14 -fold with $56 \%$ recovery. Enzyme preparation after fractionation on SephadrexG-200 chromatography followed by treatment with PEG-400 the dextransucrase activity was purified 58 -fold with recovery of $17.5 \%$. The analysis of the enzyme purification on SDS-PAGE using $10 \%$ gel showed that the purified enzyme after PEG-400 fractionation gave the single protein band corresponding to $160 \mathrm{kDa}$ as shown in Fig. 1 .

\section{Screening of serum antibody against antigenic protein dextransucrase by immunoblotting and confocal microscopy}

Antibodies were raised against the purified dextransucrase by injecting to rabbits subcutaneously as mentioned in material and methods. The serum collected from rabbit after booster immunisation was screened for the presence of the dextransucrase antibody by dot blot analysis and confocal microscopy. Three spots of purified protein, culture supernatant of $S$. mutans and BSA respectively were made on the nitrocellulose membrane and incubated with the dextransucrase antibody. The antigen antibody complex was detected using HRP-conjugated secondary goat anti-rabbit antibody. As shown in Fig. 2a, dextransucrase antibody showed strong affinity with the purified protein, culture supernatant of S. mutans demonstrating presence of antibody generated against dextransucrase. However, no reactivity was seen with the BSA which served as the control. To further validate the generation of antibody against dextransucrase, immunofluorescence by confocal microscopy of $S$. mutans cells for the affinity of the target protein was carried out. As shown in Fig. 2b, green fluorescence of $S$. mutans cells depicted significant immunoreactivity of the antibody against dextransucrase thus confirming the generation of specific antibody against antigenic protein dextransucrase.

\section{ELISA of serum antibody against enzyme protein dextransucrase}

The antibody titre of serum from immunised rabbit with dextransucrase from $S$. mutans was determined using ELISA. Antigenic protein dextransucrase of $10 \mu \mathrm{g}$ coated to wells of 96-well plate and reacted with different dilutions of antidextransucrase serum. Wells with no coating of antigen served as blank, wells treated only with primary antibody but no 
Fig. 1 SDS-PAGE showing a single band of purified dextransucrase on $10 \%$ acrylamide gel. (A) Molecular weight marker. (B) Culture supernatant of the bacterial culture. (C) Precipitated protein at $50 \%$ ammonium sulphate. (D) Precipitated protein at 55\% ammonium sulphate. (E) Protein eluted from Sephadex G-200 gel column followed by PEG fractionation

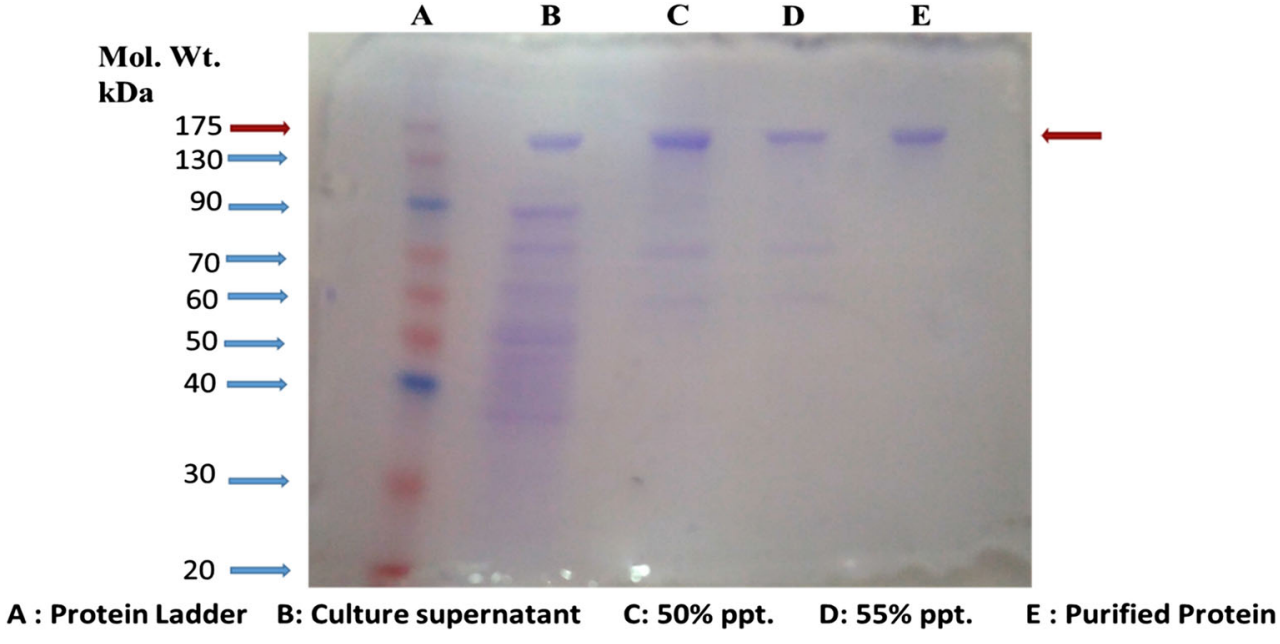

secondary antibody, served as primary control and wells treated with secondary antibody only served as secondary control. The linear regression was used to calculate $r^{2}$ that is linear correlation between serum dilution and OD. The results of ELISA as shown in Fig. 2c demonstrated that the affinity decreased with dilution. The affinity of antisera was detected at a dilution of 1:64000 and the non-coated wells showed estimate of similar to cut-off i.e. negative results.
Fig. 2 Serum antibody screening of dextransucrase immunised rabbits (a). Dot blot analysis of dextransuccrase using antiserum from immunised rabbits. (A) Purified protein. (B) Culture supernatant. (C) BSA as control. b Confocal microscopy of the S. mutans cells treated with antibody raised against dextransucrase and FITC-tagged secondary antibody. (A) Bacterial cells without antibody treatment (control). (B) Bacterial cells exposed to antibody. (C) Merged image of (A) and (B) (merge done by ImageJ software). c Antidextransucrase antibodies detected in rabbit serum by ELISA. B, Sec C and Pri C indicate blank, secondary control and primary control respectively. Values are mean $\pm \mathrm{SD}, n=3$ a

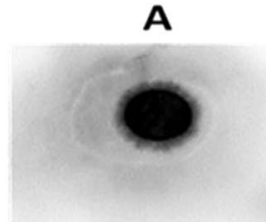

A: Purified protein B: Culture supernatant C: BSA

b

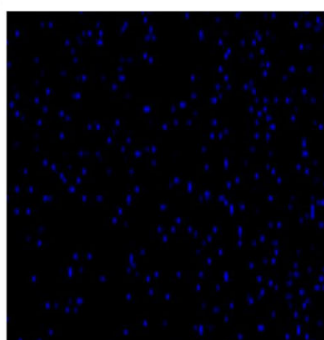

A

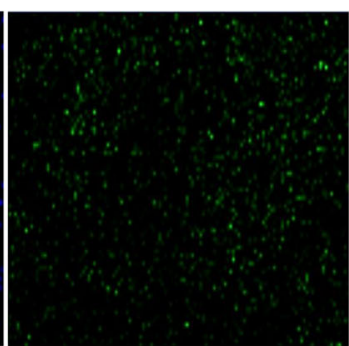

B

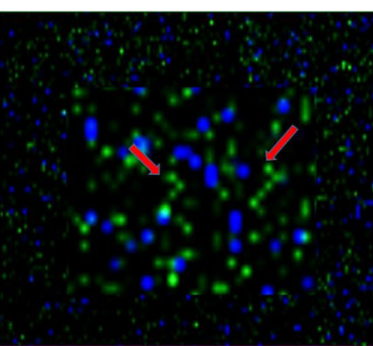

C

\section{C}

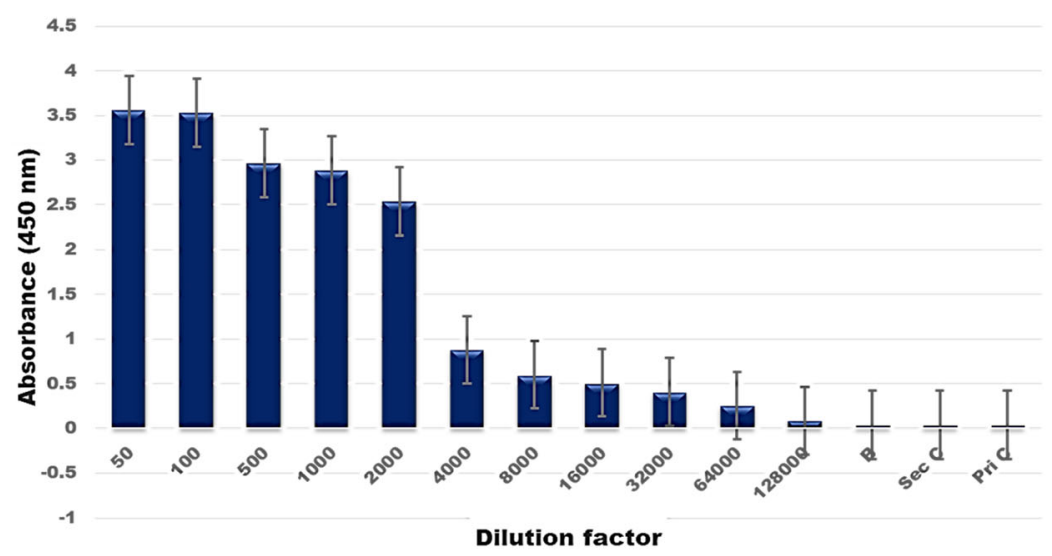




\section{Purification and characterisation of $\lg G$}

Serum IgG fraction was purified from immunised rabbit serum using affinity Protein A-Sepharose Column (Bio Vision Milpitas, USA). IgG was detected only in first four fractions collected in affinity column chromatography by measuring the absorbance at $280 \mathrm{~nm}$ using UVspectrophotometer which had concentrations of $0.299 \mathrm{mg} / \mathrm{ml}, 4.00 \mathrm{mg} / \mathrm{ml}, 0.703 \mathrm{mg} / \mathrm{ml}$ and $0.0919 \mathrm{mg} / \mathrm{ml}$ respectively. The fractions containing $\mathrm{IgG}$ were analysed on $10 \%$ SDS-PAGE which showed two clear bands of IgG having molecular weight of $50 \mathrm{kDa}$ and $25 \mathrm{kDa}$ against a prestained molecular weight marker of $175 \mathrm{kDa}$ (pink plus Gene Direx) Fig. 3a. The fractions containing purified IgG were pooled and tested by immunoblots using the samples of purified dextransucrase, culture supernatant and BSA as control. The antigen antibody complex was detected by using HRP-conjugated secondary goat anti-rabbit antibody (1:7000) dilution by enhanced chemiluminescence (ECL) system. The results are shown in Fig. 3b.
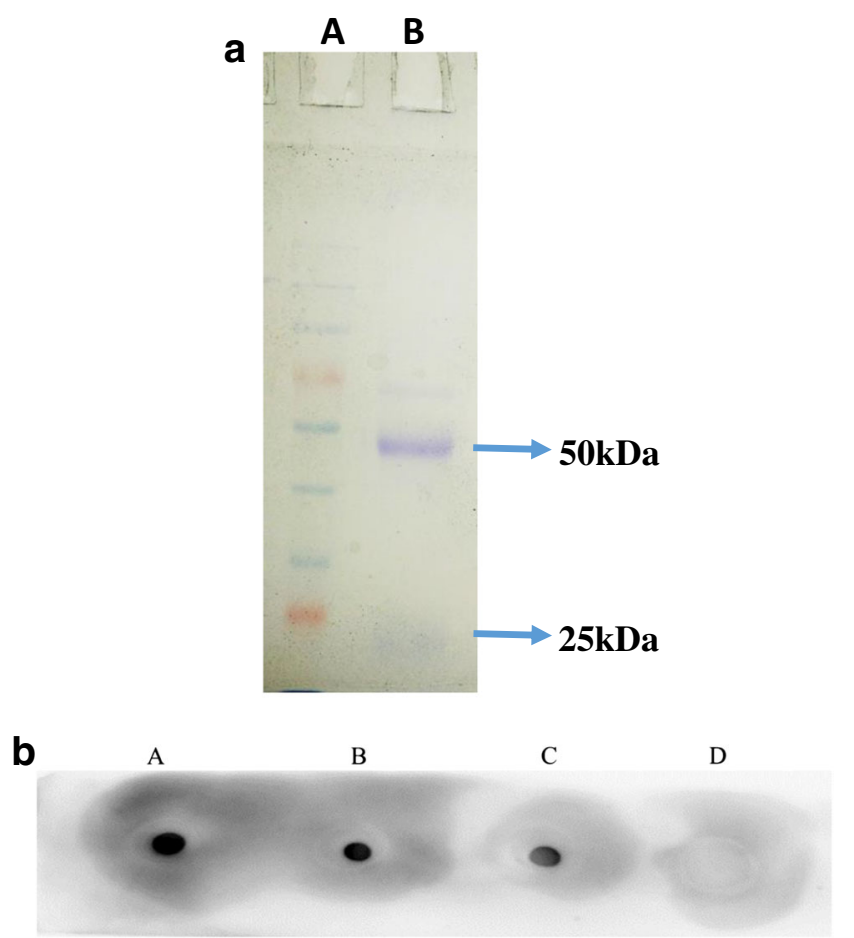

Fig. 3 Purification of IgG faction of dextransucrase antibody (a). Purified IgG fraction from serum of immunised rabbit was obtained using Protein A-sepharose column. The purified fraction was run on $10 \%$ SDS-PAGE. (A) Molecular weight marker. (B) Purified IgG showing two bands with $50 \mathrm{kDa}$ and $25 \mathrm{kDa}$. b Dot blot analysis of dextransucrase using purified IgG. Antigen antibody complex was detected on nitrocellulose membranes using HRP-conjugated secondary goat anti-rabbit antibody. (A) Purified antigen protein. (B) and (C) Culture supernatant of S. mutans. (D) BSA as a control

\section{Effect of antibody on the growth of S. mutans under in vitro conditions}

The effect of dextransucrase antibody on the growth of S. mutans was studied under in vitro conditions. S. mutans cells were grown in presence of different amounts of antibody ranging from 0 to $40 \mu \mathrm{g} / \mathrm{ml}$ for $20 \mathrm{~h}$ at $37^{\circ} \mathrm{C}$. As shown in Fig. $4,28 \mu \mathrm{g} / \mathrm{ml}$ concentration of $\operatorname{IgG}$ was found to be the minimum inhibitory concentration (MIC) which inhibited the growth of S. mutans to nearly $85 \%$ of the control indicating significant antimicrobial activity. To further study the inhibitory effect of purified antibody on the enzyme activity of dextransucrase, immunotritation was evaluated. Increasing concentrations of the IgG from 0 to $70 \mu \mathrm{g} / \mathrm{ml}$ to enzyme protein were added and enzyme activity was assayed after $30 \mathrm{~min}$ at $37^{\circ} \mathrm{C}$. As shown in Table 1, there was a progressive increase in the percentage inhibition from 2.58 to 18.22 as compared with the control. Thus, antibody against dextransucrase exhibited inhibitory effect on the activity of dextransucrase isolated from $S$. mutans.

\section{Antibody against dextransucrase from S. mutans does not show cross reactivity with mammalian tissues}

Cross reactivity of the antibody against various mammalian tissues was studied by western blot analysis. Protein samples of the liver, heart, spleen, kidney of mice, rat and liver, kidney of rabbit were analysed by western blot analysis to evaluate the cross reactivity of purified antibody with mammalian tissues Fig. 5a. Evaluation of western blot analysis showed that the anti-dextransucrase antibody in the dilution of 1:500 did not cross react with any of the mammalian tissues tested; however, there was a strong reactivity of the antidextransucrase antibody with the $S$. mutans-derived dextransucrase used as control. Western blot analysis of the human heart, liver and gall bladder was also tested for cross reactivity with anti-dextransucrase antibody. As shown in Fig.

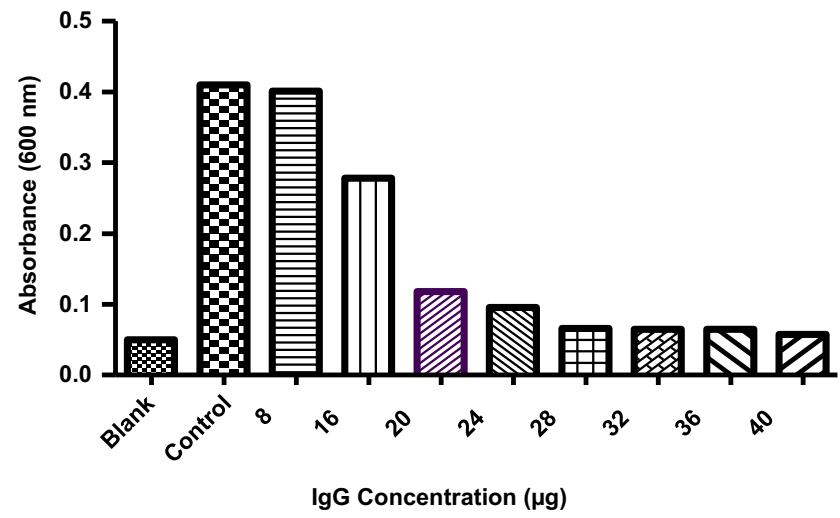

Fig. 4 Growth inhibition of $S$. mutans by purified $\operatorname{IgG}$ under in vitro conditions. The cell culture was treated with different amounts of $\mathrm{IgG}$ ranging from $(0-40 \mu \mathrm{g}$ protein) per culture tube. Bacterial growth was determined by measuring O.D at $600 \mathrm{~nm}$ after 20 -h incubation at $37^{\circ} \mathrm{C}$. The values are mean $\pm \mathrm{SD}, n=3$ 
Table 1 Immunotritation of dextransucrase from $S$. mutans using purified $\operatorname{IgG}$ fraction

\begin{tabular}{lll}
\hline $\operatorname{IgG}(\mu \mathrm{g})$ concentration & $\begin{array}{l}\text { Activity (units/mg } \\
\text { protein) }\end{array}$ & Percentage inhibition \\
\hline 0 & $0.560 \pm 0.003$ & - \\
10 & $0.545 \pm 0.003$ & 2.7 \\
20 & $0.567 \pm 0.002$ & 4.1 \\
30 & $0.523 \pm 0.002$ & 6.6 \\
40 & $0.520 \pm 0.002$ & 7.2 \\
50 & $0.500 \pm 0.003$ & 10.7 \\
60 & $0.463 \pm 0.002$ & 17.3 \\
70 & $0.458 \pm 0.002$ & 18.2 \\
\hline
\end{tabular}

The purified enzyme was treated with different concentrations of antidextransucrase IgG ranging from 0 to $70 \mu \mathrm{g}$. The enzyme activity was determined after incubation of $30 \mathrm{~min}$ at $37^{\circ} \mathrm{C}$ as described under materials and methods. Values are mean $\pm \mathrm{SD}, n=3$

$5 b$, there was no cross reactivity with these organs but showed a strong reactivity with the $S$. mutans-derived dextransucrase which served as the positive control.

\section{Cross reactivity of various bacterial strains with serum antibody of dextransucrase}

Immunoblot analysis of cell extracts from gram-positive and gram-negative bacterial strains such as $S$. oralis, L. acidophilus, S. aureus, E. faecalis, E. coli and S. typhimurium respectively was also studied to check the reactivity of these strains with dextransucrase antibody. As shown in Fig. 6, there was little reactivity of antibody raised against dextransucrase with $L$. acidophillus and S. aureus and no reactivity with other bacterial strains confirming the specificity of the antibody against $S$. mutans.

\section{Anti-dextransucrase antibodies reduced the biofilm formation in crystal violet microplate assay}

The anti-biofilm formation tendency of antibody raised against dextransucrase from $S$. mutans was investigated by crystal violet assay. The $S$. mutans cells were grown under in vitro conditions treated with $20 \mu \mathrm{g}$ purified IgG. The assay was carried out in triplicates in three sets of samples as blank, treated and control in triplicates in 96-well plate and incubated for $20 \mathrm{~h}$ at $37^{\circ} \mathrm{C}$. As shown in Fig. 7, the value of crystal violet assay of antibody treated sample was 0.090 as compared with control 1.232 as quantified by photometric estima-

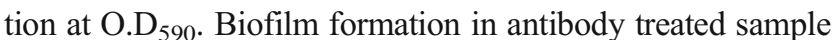
was reduced by $92.6 \%$ as compared with the control and statistically significant reduction in biofilm formation was observed at $28 \mu \mathrm{g} / \mathrm{ml}$ of serum IgG.
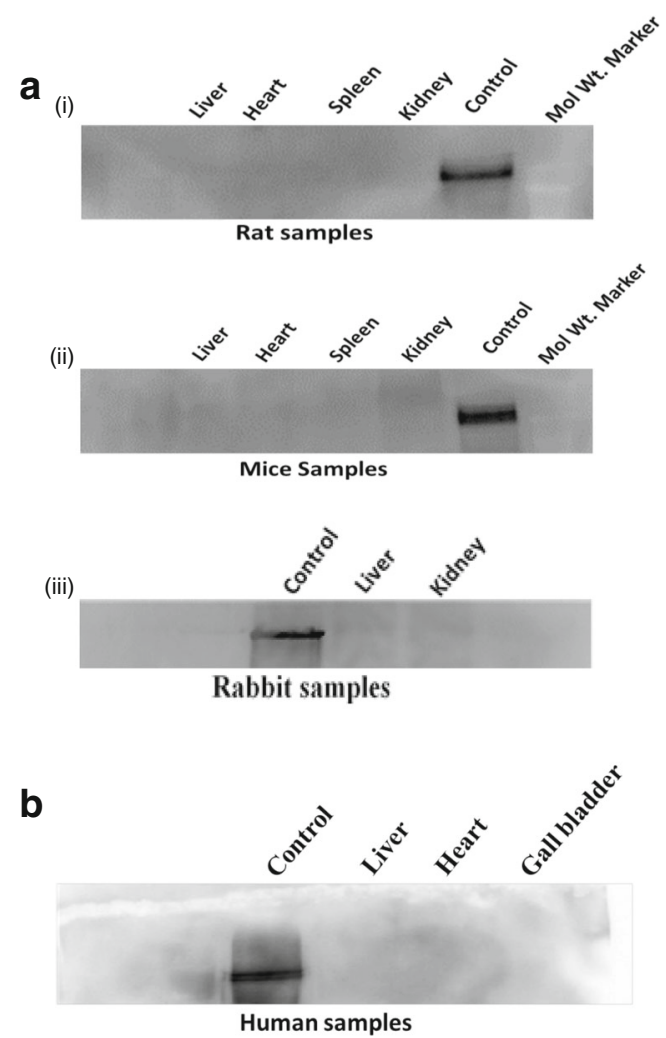

Fig. 5 Assay of cross reactivity of dextransucrase antibody with various mammalian tissues (a). Immunoblots of tissues samples from liver, heart, spleen and kidney of rat (i), mice (ii) and rabbit (iii). Purified dextransuccrase was used as the control. The tissue protein was resolved on SDS-PAGE by using $10 \%$ gels, transferred onto nitrocellulose membrane and detected by western blot analysis using purified dextransucrase antibody (1:500) dilution followed by HRPconjugated secondary goat anti-rabbit antibody (1:7000) dilution. The blots were developed by ECL system. b The reactivity of dextransucrase antibody with tissues proteins of the heart, liver and gall bladder from humans by immunoblot analysis. Purified dextransuccrase was used as control.

\section{Dextransucrase antibody showed significant inhibition of glucosyltransferase activity in S. mutans}

Dextransucrase have both hydrolytic and transferase activity. It catalyses the transfer of glucosyl residues from sucrose to dextrans. These results showed that enzyme activity was 0.212 units $/ \mathrm{mg}$ protein in control which was reduced to 0.0576 units $/ \mathrm{mg}$ protein in the presence of $30 \mu \mathrm{g}$ of $\mathrm{IgG}$, indicating a decrease of $72.8 \%$ in glucosyltransferase activity under these conditions (Fig. 8).

\section{Discussion}

S. mutans is the well-established etiological agent in the pathogenesis of dental caries. The virulence traits by which infection is established includes biofilm formation by sucrose dependent and independent means, adherence, aciduricity, 


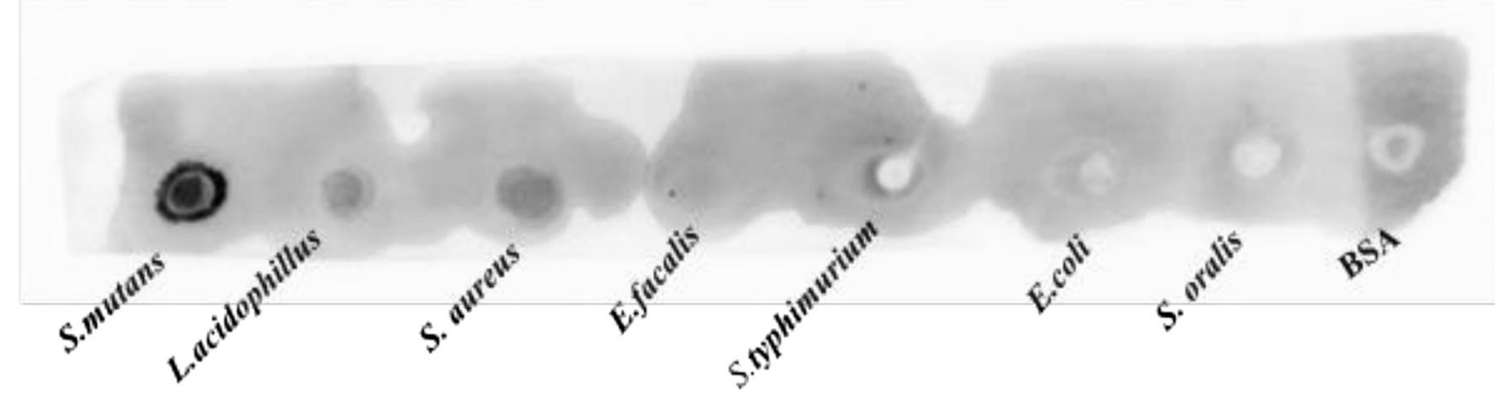

Fig. 6 Reactivity of dextransuccrase antibody with different bacterial strains (both gram-positive and gram-negative strains). The bacterial strains used were $S$. mutans MTCC-890, L. acidophilus MTCC-10307,

acidogenicity and hydrophobic interactions (Hasan et al. 2014; Ferreira et al. 2016). Immune intervention against dental caries has been pursued for the last many years to develop a potent and effective vaccine that may help to combat this chronic infectious disease (Zhang 2013).

Several cell surface substances of $S$. mutans that have been used for vaccine preparation include glucosyltransferases, adhesins and glucan-binding proteins (Giasuddin et al. 2017). Efforts are being made to raise antibodies against various S. mutans antigens and to examine their effect on caries formation (Hajishengallis and Michalek 1999). In the previous studies, whole cells of the mutans streptococci were used as possible vaccine for the dental caries. Surface substances of $S$. mutans including glucosyltransferases (GTFs), lipoteichoic acid, antigen

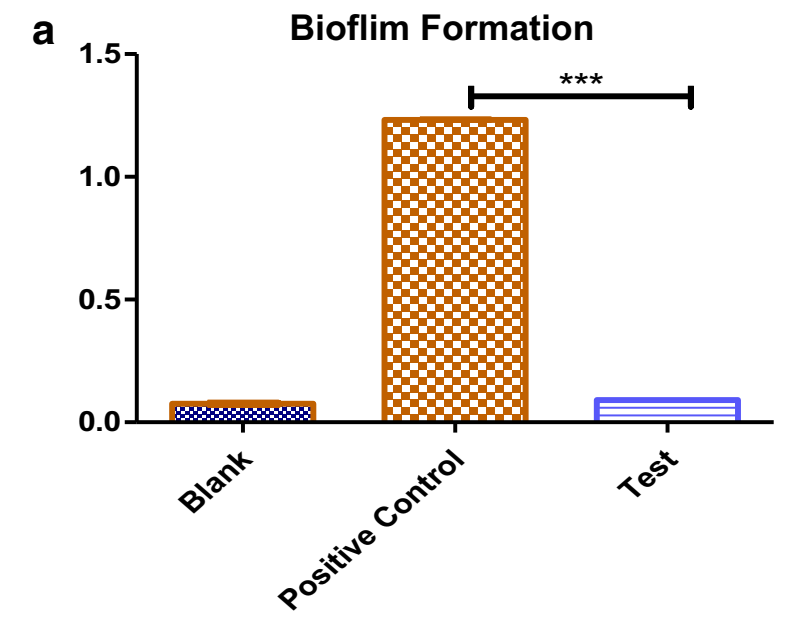

b

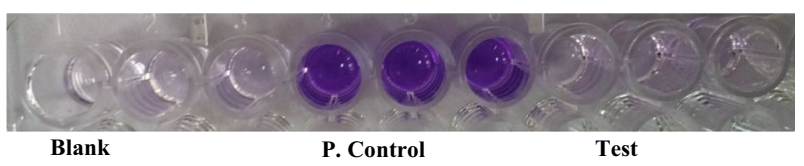

Fig. 7 a Effect of dextransucrase antibody on biofilm formation by $S$. mutans under in vitro conditions. The cells were treated with antibody $(28 \mu \mathrm{g})$. Data are mean $\pm \mathrm{SD} n=3$. The bar represent $p$ value $<0.001$ compared with control. Blank = only culture media, positive control $=S$. mutans culture without dextransucrase antibody, test $=$ S. mutans culture with dextransucrase antibody. b Biofilm formation assay performed in 96-well plate using crystal violet staining of biofilm.
S. aureus ATCC-9144, E. faecalis MTCC-439, S. typhimurium NCTC74, E. coli MTCC-1610 and $S$. oralis MTCC-2696 respectively

A (29-kDa protein), antigen C (70-kDa protein), antigen D (13$\mathrm{kDa}$ protein), AgI/II (190-kDa protein), AgIII (39-kDa protein) and Gbp (glucan-binding proteins (Koga et al. 1995; Kuramitsu 1993) play crucial role in pathogen and host interaction. Kim et al. (2012) have also reported the formation monoclonal antibody against clonal fragment of glucosyltransferase B in S. mutans GS-5 and showed its inhibitory activity against the enzyme. Thus, these surface molecules have attracted much attention for the development of vaccine against dental caries.

In the present study, we generated antibodies against dextransucrase principally involved in the metabolism of sucrose which is the main substrate of $S$. mutans in establishing the dental caries. Dextransucrase was purified and antibodies against it were raised in rabbits. The raised antibodies were checked for affinity with dextransucrase using dot blot assay which showed significant reactivity and further validated by immunofluorescence using confocal microscopy which confirmed specific binding of dextransucrase antibody with the cells of $S$. mutans. Dextransucrase helps $S$. mutans in the

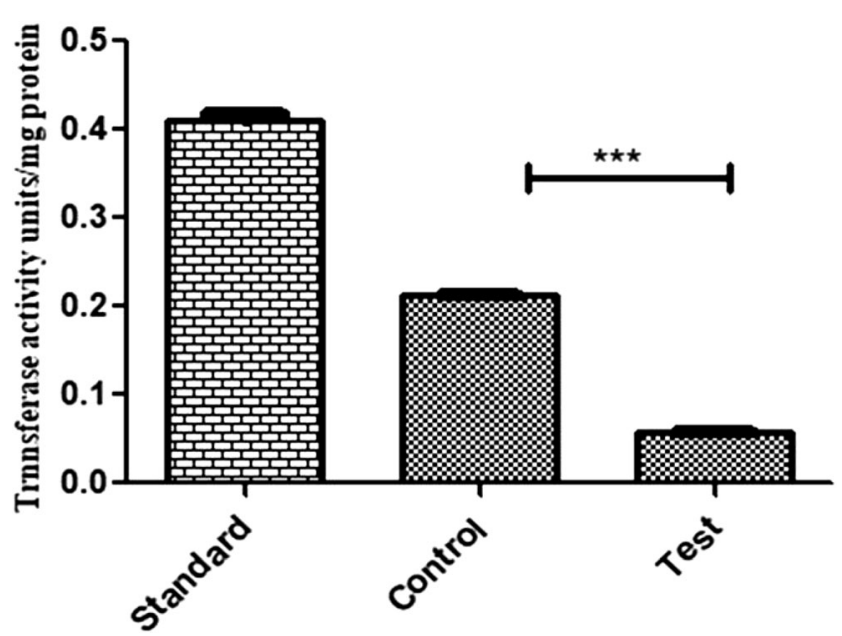

Fig. 8 Effect of anti-dextransucrase antibody on the glucosyltransferase activity of dextransucrase enzyme. Transferase activity was determined by measuring the amount of sugar content after treating the enzyme dextransucrase with antibody. Standard=Assay system contained glucose with no dextran, no enzyme and no antibody. Control = Enzyme + dextran Test $=$ Enzyme + Dextran + antibody. Data are mean $\pm \mathrm{SD}, n=3$ 
metabolism of sucrose for its growth and producing waterinsoluble glucans with mixed $\alpha-1,3$ and $\alpha-1,6$ linkages (Moye et al. 2014) which are involved in the attachment of $S$. mutans on the tooth surfaces and in the biofilm formation (Bowen and Koo 2011) leading to caries formation. Immunotitration of dextransucrase with purified dextransucrase antibody showed a progressive increase in percentage inhibition of enzyme activity, although the antibody titre was high, presumably due to its polyclonal nature. Also it was observed that the growth of $S$. mutans in the presence of different concentrations of antibody under in vitro conditions was inhibited, which correlated with the inhibitory effect on dextransucrase activity; however, the values were quantitatively distinct. This is in agreement to the studies of Culshaw et al. (2007) on anticaries protection after immunisation of animals with intact GTF. Transferase activity of dextransucrase also showed a significant reduction in presence of anti-dextransuccrase antibody which may help in reducing glucan formation.

Biofilm formation proceeds with the attachment of bacterial cells to the tooth surface and subsequent formation of multilayered cell clusters (Challan et al. 2006; Wen and Burne 2002). The biofilm is stabilised when the bacterial cells in the three-dimensional structure grow vertically and get connected through extracellular polysaccharides (Ansari et al. 2017) produced by the metabolism of sucrose with the action of dextransucrase. Song et al. (2015) have shown that biofilm formation is strongly dependent upon the surface adhesion and hydrophobicity of the material. More recently, Nilsson et al. (2019) have shown that oxidative stress plays a role in the antibiotic tolerance of S. mutans biofilm. In our study, the efficacy of dextransucrase antibody on biofilm formation was studied using crystal violet microplate assay in which cells were grown in saliva coated wells for $20 \mathrm{~h}$ which demonstrated that there was $92.6 \%$ reduction in the biofilm formation in antibody-treated samples as compared with control suggesting that the dextransucrase antibody has inhibited enzymatic activity of dextransucrase and thus disrupted the bacterial adherence and subsequent aggregation of cell clusters leading to biofilm formation.

Although various types of vaccines have been developed and tried for caries prevention like whole cell vaccine, conjugate vaccine, synthetic vaccine and DNA vaccine etc. and showed promising results for the protection against dental caries, however, it was reported that antibodies generated showed cross reactivity with human heart tissues and skeleton muscle tissues (Ayakawa et al. 1985). This was further confirmed by other investigators and these immunologically cross-reactive polypeptides were found in the cell membrane of $S$. mutans (Giasuddin et al. 2017). Subunit vaccines have also been tried to overcome the cross reactivity but were reported having less immunogenicity (Zhang 2013). It is also assumed that besides S. mutans, other oral bacteria also play a role in the pathogenesis of dental caries although the mechanism is not established. Nevertheless, the inhibitory effect of dextransucrase antibodies against several cariogenic factors of S. mutans may be helpful in formulating strategies to combat the disease (Alam et al. 2018). Present data showed that the antibodies generated did not cross react with protein extracts from the liver, heart, lungs and kidneys of mice, rat and rabbit by western blot analysis. Protein extracts from the human heart, liver and gall bladder were also checked for cross reactivity with the dextransucrase antibodies by western blot analysis which revealed negative results.

We further investigated the cross reactivity of dextransucrase antibody with various bacterial strains and this specificity was tested by using total protein extract of various gram-positive and gram-negative bacterial strains. Protein extracts form S. mutans, S. oralis, L. acidophilus, S. aureus, E. faecalis, S. typhimurium and $E$. coli were evaluated for cross reactivity by immunoblot analysis and the results have shown little reactivity with $L$. acidophilus and $S$. aureus other than $S$. mutans and there was no reactivity with the other bacterial strains. The reactivity with the L. acidophilus and S. aureus suggests a similar epitope recognised between two strains. Since the dextransucrase antibody recognised the similar epitopes on the two oral strains, it can be predicted that anti-dextransucrase antibodies raised against $S$. mutans could recognise other species of the oral cavity, thereby strengthens the support to dextransucrase as a candidate vaccine against dental caries and shared epitopes between cariogenic strains can show better efficacy in clinical trials.

Thus, the data highlights the importance of antibody against dextransucrase which has inhibitory effect on the growth of $S$. mutans and worked effectively against biofilm formation. Our preliminary observations also indicated that dextransucrase antibodies when added to the growth media inhibited acid production and reduced hydrophobicity of $S$. mutans (results not shown) which further corroborated the anticariogenic properties of the dextransucrase antibodies. Moreover, examination of various animal and human tissues showed no cross reactivity with dextransucrase antibody which implies that they may have no harmful physiological effects in the humans, thus may prove a promising antigen for developing anticariogenic agent. Further studies to characterise the cariogenic effects of antibody against dextransucrase are underway to ascertain these findings.

Acknowledgements Shabeer Ahmad Rather is a recipient of senior research fellowship from ICMR New Delhi. We thank to Mr. Naveed Parvaiz of department of Zoology Panjab University, Chandigarh, India, for providing tissue samples of mice and rat and Dr. Chetan for rabbit tissues samples. We appreciate the help of Professor Praveen Rishi of department of Microbiology Panjab University, Chandigarh, India, for providing bacterial strains $S$. aureus, L. acidophilus, S. typhimurium, E. coli and E. faecalis.

Authors' contributions S.A.R wrote the main manuscript and performed experiments, A.M contributed in concept design and/or analysis and interpretation of data and revising it critically for important intellectual content and S.C.S provided culture facilities and reviewed the article for important inputs. The article was reviewed for final submission by all authors. 


\section{Compliance with ethical standards}

The study was approved by Central Animal Ethics Committee Panjab University Chandigarh and experiments were performed in compliance with the guidelines of Committee for the Purpose of Control and Supervision of Experiments on Animals (CPCSEA). Human tissues were obtained from the histopathology department of Postgraduate Institute of Medical Education and Research Chandigarh in compliance with the standards of institutional ethical committee.

Methods statement Authors declare that all experiments and procedures performed with animals were performed in accordance with relevant guidelines and regulations of the Institutional Animal ethics Committee of Panjab University, Chandigarh, India.

Competing interests The authors declare that they have no conflict of interest.

\section{References}

Alam MK, Zheng L, Liu R, Papagerakis S, Papagerakis P, Geyer CR (2018) Synthetic antigen-binding fragments (Fabs) against $S$. mutans and S. sobrinus inhibit caries formation. Sci Rep 8: 10173. https://doi.org/10.1038/s41598-018-28240-0

Ansari JM, Abraham NM, Massaro J, Murphy K, Smith-Carpenter J, Fikrig E (2017) Anti-biofilm activity of a self-aggregating peptide against Streptococcus mutans. Front Microbiol 8:488. https://doi. org/10.3389/fmicb.2017.00488

Ayakawa GY, Siegel JL, Crowley PJ, Bleiweis AS (1985) Immunochemistry of the Streptococcus mutans BHT cell membrane: detection of determinants cross-reactive with human heart tissue. Infect Immun 48:280-286

Bao R, Yang JY, Sun Y, Zhou DH, Yang Y, Li YM, Cao Y, XiaoY LW, Yu J, Zhao BL, Zhong MH, Yan HM (2015) Flagellin-PAc fusion protein inhibits progression of established caries. J Dent Res 94:955960. https://doi.org/10.1177/0022034515582224

Bhattacharya S, Virani S, Zarvo M, Hass JG (2003) Inhibition of Streptococcus mutans and other oral streptococci by Hop (Humulus lupulus L.) constituents. Econ Bot 57:118-125. https:// doi.org/10.1663/0013-0001(2003)057[0118:IOSMAO]2.0.CO;2

Bowen WH, Koo H (2011) Biology of Streptococcus mutans-derived glucosyltransferases: role in extracellular matrix formation of cariogenic biofilms. Caries Res 45:69-86. https://doi.org/10.1159/ 000324598

Campion EM, Loughran ST, Walls D (2017) Protein quantitation and analysis of purity. Methods Mol Biol 1485:225-255. https://doi. org/10.1007/978-1-4939-6412-3_12

Cao XX, Fan J, Chen J, Li YH, Fan MW (2016) Immunogenicity and prediction of epitopic region of antigen Ag I/II and glucosyltransferase from Streptococcus mutans. J Huazhong Univ Sci Tech Med Sci 36:416-421. https://doi.org/10.1007/s11596-0161602-y

Challan BS, Gal L, Margiewes S, Garmyn D, Piveteau P, Guzzo J (2006) Assessment of the roles of LuxS, S-ribosyl homocysteine, and auto inducer 2 in cell attachment during biofilm formation by Listeria monocytogenes EGD-e. Appl Environ Microbiol 72:2644-2650. https://doi.org/10.1128/AEM.72.4.2644-2650.2006

Chen F, Wang D (2010) Novel technologies for the prevention and treatment of dental caries: a patent survey. Expert Opin Ther Pat 20:681694. https://doi.org/10.1517/13543771003720491

Craig A (1998) Antimicrobial resistance-danger signs all around. Tenn Med 91:433-435
Culshaw S, Larosa K, Tolani H, Han X, Eastcott JW, Smith DJ, Taubman MA (2007) Immunogenic and protective potential of mutans streptococcal glucosyltransferase peptide constructs selected by major histocompatibility complex class II allele binding. Infect Immun 75:915-923. https://doi.org/10.1128/IAI.01582-06

Dubois M, Gilles KA, Hamilton JK, Rebers PA, Smith F (1956) Colorimetric method for determination of sugars and related substances. Anal Chem 28:350-356. https://doi.org/10.1021/ac60111a017

Fan MW, Bian Z, Peng ZX, Zhong Y, Chen Z, Peng B, Jia R (2002) A DNA vaccine encoding a cell-surface protein antigen of Streptococcus mutans protects gnotobiotic rats from caries. J Dent Res 81:784-787. https://doi.org/10.1177/0810784

Ferreira EL, Batista MT, Cavalcante RC, Pegos VR, Passos HM, Silva DA, Balan A, Ferreira LC, Ferreira RC (2016) Sublingual immunization with the phosphate-binding-protein (PstS) educes oral colonization by Streptococcus mutans. Mol Oral Microbiol 31:410-422. https://doi.org/10.1111/omi.12142

Giasuddin ASM, Huda SN, Jhuma KA, Haq AMM (2017) Dental caries vaccine availability: challenges for the 21 st century. J Immunoass Immunother 1:002

Goyal D (2015) Studies on the interactions of plant polyphenols with dextransucrase of Streptococcus mutans: anticariogenic perspective. $\mathrm{PhD}$ thesis, Panjab University Chandigarh

Hajishengallis G, Michalek SM (1999) Current status of a mucosal vaccine against dental caries. Oral Microbiol Immunol 14:1-20. https:// doi.org/10.1034/j.1399-302x.1999.140101.x

Hasan S, Singh K, Danisuddin M, Verma PK, Khan AU (2014) Inhibition of major virulence pathways of Streptococcus mutans by quercitrin and deoxynojirimycin: a synergistic approach of infection control. PLoS One 9:e91736. https://doi.org/10.1371/journal.pone.0091736

Jarvinen H, Tenovuo J, Huovinen P (1993) In vitro susceptibility of Streptococcus mutans to chlorhexidine and six other antimicrobial agents. Antimicrob Agents Chemother 37:1158-1159. https://doi. org/10.1128/aac.37.5.1158

Kim MA, Lee MJ, Jeong HK, Song HJ, Jeon HJ, Lee KY, Kim JG (2012) A monoclonal antibody specific to glucosyltransferase B of Streptococcus mutans GS-5 and its glucosyltransferase inhibitory efficiency. Hybridoma (Larchmt) 31:430-435. https://doi.org/10. 1089/hyb.2012.0047

Koga T, Yamashita Y, Nakano Y, Kawasaki M, Oho T, Yu H, Nakai M, Okahashi N (1995) Surface proteins of Streptococcus mutans. Dev Biol Stand 85:363-369

Kruger C (2004) Passive immunisation against oral pathogen. From the division of clinical immunology at the department of laboratory medicine and center for oral biology at NOVUM, institute of odontology. Karolinska institute, Stockholm, Sweden

Kt S, Kmk M, N B, Jimson S, R (2013) Dental caries vaccine - a possible option? J Clin Diagn Res 7:1250-1253. https://doi.org/10.7860/ JCDR/2013/5246.3053

Kuramitsu HK (1974) Characterization of cell-associated dextransucrase activity from glucose-grown cells of Streptococcus mutans. Infect Immun 10:227-235

Kuramitsu HK (1993) Virulence factors of mutans streptococci: role of molecular genetics. Crit Rev Oral Biol Med 4:159-176. https://doi. org/10.1177/10454411930040020201

Laemmli UK (1970) Cleavage of structural proteins during the assembly of the head of bacteriophage T4. Nature 227:680-685. https://doi. org/10.1038/227680a0

Liu F, Yang J, Zhang Y, Zhou D, Chen Y, Gai W, Shi W, Li Q, Tien P, Yan H (2010) Recombinant flagellins with partial deletions of the hypervariable domain lose antigenicity but not mucosal adjuvancy. Biochem Biophys Res Commun 392:582-587. https://doi.org/10. 1016/j.bbrc.2010.01.077

Loesche WJ (1996) Microbiology of dental decay and periodontal disease. Medical microbiology, 4th edn. University of Texas Medical Branch at Galveston, Galveston Chapter 99 
Lynch DJ, Michalek SM, Zhu M, Drake D, Qian F, Banas JA (2013) Cariogenicity of Streptococcus mutans glucan-binding protein deletion mutants. Oral Health Dent Manag 12:191-199

Mahmood A, Mahmood S, DeSchryver-Kecskemeti K, Alpers DH (1993) Characterization of proteins in rat and human intestinal surfactant-like particles. Arch Biochem Biophys 300:280-286. https://doi.org/10.1006/abbi.1993.1039

Merritt JH, Kadouri DE, O'Toole GA (2005) Growing and analyzing static biofilms. Curr Protoc Microbiol Chapter 1: Unit 1B.1. https://doi.org/10.1002/9780471729259.mc01b01s00

Moye ZD, Zeng L, Burne RA (2014) Fueling the caries process: carbohydrate metabolism and gene regulation by Streptococcus mutans. J Oral Microbiol 6:24878. https://doi.org/10.3402/jom.v6.24878

Mukasa H, Shimamura A, Tsumori H (1979) Effect of salts on waterinsoluble glucan formation by glucosyltransferase of Streptococcus mutans. Infect Immun 23:564-570

Nilsson M, Jakobsen TH, Givskov M, Twetman S, Tolker-Nielsen T (2019) Oxidative stress response plays a role in antibiotic tolerance of Streptococcus mutans biofilms. Microbiology 165:334-342. https://doi.org/10.1099/mic.0.000773

Song F, Koo H, Ren D (2015) Effects of material properties on bacterial adhesion and biofilm formation. J Dent Res 94:1027-1034. https:// doi.org/10.1177/0022034515587690

Talbman MA, Smith DJ (1974) Effects of local immunization with Streptococcus mutans on induction of salivary immunoglobulin A antibody and experimental dental caries in rats. Infect Immun 9: 1079-1091

Vera-Cabrera L, Rendon A, Diaz-Rodriguez M, Handzel V, Laszlo A (1999) Dot blot assay for detection of antidiacyltrehalose antibodies in tuberculosis patients. Clin Diagn Lab Immunol 6:686-689
Wen ZT, Burne RA (2002) Functional genomics approach to identifying genes required for biofilm development by Streptococcus mutans. Appl Environ Microbiol 68:1196-1203. https://doi.org/10.1128/ aem.68.3.1196-1203.2002

Xu QA, Yu F, Fan MW, Bian Z, Chen Z, Peng B, Jia R, Guo JH (2007) Protective efficacy of a targeted anti-caries DNA plasmid against cariogenic bacterial infections. Vaccine 25:1191-1195. https://doi. org/10.1016/j.vaccine.2006.10.013

Yan H (2013) Salivary IgA enhancement strategy for development of a nasal-spray anti-caries mucosal vaccine. Sci China Life Sci 56:406413. https://doi.org/10.1007/s11427-013-4473-5

Yang J, Sun Y, Bao R, Zhou D, Yang Y, Cao Y, Yu J, Zhao B, Li Y, Yan H, Zhong M (2017) Second-generation flagellin-rPAc fusion protein, KFD2-rPAc, shows high protective efficacy against dental caries with low potential side effects. Sci Rep 7:11191. https://doi.org/10. 1038/s41598-017-10247-8

Yang H, Yan Z, Zhang Z, Realivazquez A, Ma B, Liu Y (2019) Anticaries vaccine based on clinical cold-adapted influenza vaccine: a promising alternative for scientific and public-health protection against dental caries. Med Hypotheses 126:42-45. https://doi.org/ 10.1016/j.mehy.2019.03.006

Zhang S (2013) Dental caries and vaccination strategy against the major cariogenic pathogen, Streptococcus mutans. Curr Pharm Biotechnol 14:960-966. https://doi.org/10.2174/1389201014666131226144339

Publisher's note Springer Nature remains neutral with regard to jurisdictional claims in published maps and institutional affiliations. 